\title{
Evaluation of immunoprotective effects of recombinant protein and DNA vaccine based on Eimeria tenella surface antigen 16 and 22 in vivo
}

\author{
Pengfei Zhao ${ }^{1}$. Chaofei Wang ${ }^{1}$. Jun Ding ${ }^{2}$. Chengfeng Zhao ${ }^{3}$ - Yingjun Xia ${ }^{1} \cdot$ Yanli Hu ${ }^{1} \cdot$ Li Zhang $^{1} \cdot$ Yanqin Zhou $^{1}$. \\ Junlong Zhao ${ }^{1} \cdot$ Rui Fang ${ }^{1}$
}

Received: 21 December 2020 / Accepted: 25 February 2021 / Published online: 10 March 2021

(C) The Author(s), under exclusive licence to Springer-Verlag GmbH, DE part of Springer Nature 2021

\begin{abstract}
Coccidiosis triggered by Eimeria tenella is accompanied by haemorrhagic caecum and high morbidity. Vaccines are preferable choices to replace chemical drugs against coccidiosis. Surface antigens of apicomplexan parasites can adhere to host cells during the infection process. Therefore, truncated fragments coding E. tenella surface antigen 16 (EtSAG16) and 22 (EtSAG22) were cloned into pET-28a prokaryotic vector to express recombinant protein 16 (rEtSAG16) and 22 (rEtSAG22), respectively. Likewise, pEGFP-N1-EtSAG16 and pEGFP-N1-EtSAG22 plasmids were constructed using pEGFP-N1 eukaryotic vector. Further, pEGFP-N1-EtSAG4-16-22 multiple gene plasmid carrying EtSAG4, 16 and 22 were designed as cocktail vaccines to study integral immunoprotective effects. Western blot and RT-PCR (reverse transcription) assay were performed to verify expressions of EtSAG16 and 22 genes. Immunoprotective effects of recombinant protein or DNA vaccine were evaluated using different doses ( 50 or $100 \mu \mathrm{g}$ ) in vivo. All chickens in the vaccination group showed higher cytokine concentration (IFN- $\gamma$ and IL-17), raised IgY antibody level, increased weight gain, lower caecum lesion score and reduced oocyst shedding compared with infection control groups $(p<0.05)$. The highest anticoccidial index (ACI) value 173.11 was from the pEGFP-N1-EtSAG4-16-22 plasmid $(50 \mu \mathrm{g})$ group. In conclusion, EtSAG16 and 22 might be alternative candidate genes for generating vaccines against E. tenella infection.
\end{abstract}

Keywords Eimeria tenella $\cdot$ Recombinant protein $\cdot$ DNA vaccine $\cdot$ Cocktail vaccine $\cdot$ Immunoprotective

Section Editor: Berit Bangoura

Rui Fang

fangrui19810705@163.com

Pengfei Zhao

pengfeizhao0513@163.com

Chaofei Wang

1228147748@qq.com

Jun Ding

375979757@qq.com

Chengfeng Zhao

13871896828@163.com

Yingjun Xia

2018302120125@webmail.hzau.edu.cn

Yanli $\mathrm{Hu}$

hly202009@163.com
Li Zhang

zhangli951010@163.com

Yanqin Zhou

yanqinzhou@mail.hzau.edu.cn

Junlong Zhao

zhaojunlong@mail.hzau.edu.cn

1 State Key Laboratory of Agricultural Microbiology, College of Veterinary Medicine, Huazhong Agricultural University, Wuhan 430070, Hubei, China

2 Animal Disease Prevention and Control Center, Jingshan 431800, Hubei, China

3 Animal Disease Prevention and Control Center, Anlu 432600, Hubei, China 


\section{Introduction}

Coccidiosis caused by Eimeria species features with severe intestinal pathology. E. tenella is the most pathogenic for chickens among seven Eimeria species and causes enormous economic loss in the poultry industry (Blake and Tomley 2014; Reid et al. 2014; Williams 1998; Williams 1999).

At present, prophylactic control of coccidiosis is mainly dependent on drug and live attenuated coccidium vaccine. Nevertheless, overuse of anticoccidial medicines causes serious drug resistance (Lesa et al. 2014). Although live attenuated anticoccidial vaccine imparts adequate protection for chicken against coccidiosis, there are risks of virulence recovery (Lai et al. 2011; Shirley 2010; Williams 2002). Therefore, there is an urgent need to search for new coccidiosis control methods (Chapman and Jeffers 2014).

Recombinant protein and DNA-based vaccines have been widely used to protect against viruses and bacteria (Ivory and Chadee 2004; Lillehoj et al. 2005). Parasitologists also have begun to explore recombinant protein and DNA-based vaccines for coccidiosis. Recombinant protein and DNA vaccines derived from E. tenella SAG4 induce high expression of IFN- $\gamma$, IL-17 and IgY antibody in serum and protect chickens against $E$. tenella infection (Zhao et al. 2020). The anticoccidial index (ACI) value of E. acervulina microneme 5 gene recombinant protein is more than 160 , indicating adequate protection for chickens (Zhang et al. 2014). Glyceraldehyde 3-phosphate dehydrogenase (GAPDH) of coccidia can stimulate cell-mediated immunity against three Eimeria species infection (Tian et al. 2017). Surface antigens (SAGs) of E. tenella are composed of a signal peptide at the N-terminal end and a hydrophobic glycosylphosphatidylinositol (GPI)-anchored protein at the C-terminal end (Ajioka et al. 1998; Tabarés et al. 2004). They are involved in adhesion and invasion in host-parasite interaction (Lekutis et al. 2001; Ramly et al. 2013; Tabarés et al. 2004). EtSAG16 and 22 genes belong to multi-gene family B (containing EtSAG13-23 gene) and express in second-generation merozoites (Tabarés et al. 2004). SAG1 antigen of Toxoplasma gondii can stimulate cytotoxic CD8+ T cells to produce abundant IFN- $\gamma$ and IL12 (Bülow and Boothroyd 1991). EtSAG1 (TA4) and EtSAG4 antigens of $E$. tenella sporozoites are reactive with serum from chicken infected with $E$. tenella oocysts (Jahn et al. 2009; Zhao et al. 2020).

However, immunogenicity and immunoprotective effects of EtSAG16 and 22 genes remained unknown. Therefore, in the present study, EtSAG16 and 22 genes were cloned into pET-28a prokaryotic vector to express rEtSAG16 and 22 protein in Escherichia coli. Similarly, pEGFP-N1-EtSAG16 and pEGFP-N1-EtSAG22 plasmids were constructed using pEGFP-N1 eukaryotic vector and amplified in 293T cells. Besides, a plasmid carrying multiple genes (pEGFP-N1-
EtSAG4-16-22) was designed as a cocktail vaccine to study synergistic effects among EtSAG genes. Finally, the immunoprotective effects of EtSAG16 and EtSAG22 recombinant proteins and DNA vaccine were evaluated using an animal model.

\section{Materials and methods}

\section{Animals and parasite material}

One-day-old cobb broilers 500 (numbers $=140$ ) were bought from ZhengKang livestock and poultry Co., Ltd (Jingzhou, China) and were free of vaccination. All chickens were fed in the coccidia-free environment and supplied with fodder and water ad libitum (approval number: 42000400002483). E. tenella oocysts were provided by the parasitic laboratory of Huazhong Agricultural University, multiplied in specific pathogen-free (SPF) chicken and stored under condition of $2.5 \%$ potassium dichromate at $4^{\circ} \mathrm{C}$ (Smith and Ruff 1975).

\section{Cloning and plasmid construction of EtSAG16 and EtSAG22 genes}

Total RNA was extracted from E. tenella sporozoites $(5.0 \times$ $10^{4}$ ) according to specifications of TRIzol reagent (Invitrogen, Carlsbad, CA, USA). Complementary DNA (cDNA) was amplified by reverse transcription-polymerase chain reaction (RT-PCR) using RevertAid First Strand cDNA Synthesis Kit (Thermo Fisher Scientific, Waltham, MA, USA). Hydrophobic GPI signal-anchor peptide and signal peptide gene sequence can interfere with the expression of recombinant proteins usually. Therefore, truncated fragments of EtSAG4 (number 22-237 amino acid) (Zhao et al. 2020), 16 (number 23-253 amino acid) and 22 (number 26-246 amino acid) without C-terminal hydrophobic GPI signal-anchor peptide and $\mathrm{N}$-terminal hydrophobic signal peptide were obtained by the PCR method. PCR reaction was performed under the following condition: $95^{\circ} \mathrm{C}$ for $5 \mathrm{~min}$; following by 35 cycles of $95^{\circ} \mathrm{C}$ for $30 \mathrm{~s}, 56^{\circ} \mathrm{C}$ for $30 \mathrm{~s}$, and $72^{\circ} \mathrm{C}$ for $30 \mathrm{~s}$; finally extension at $72^{\circ} \mathrm{C}$ for $10 \mathrm{~min}$; refrigeration at $15^{\circ} \mathrm{C}$ for $5 \mathrm{~min}$. Primers of PCR are shown in Table 1. Plasmids were constructed by homologous recombination in this study. Truncated EtSAG16 and EtSAG22 were transferred into pET-28a prokaryotic or pEGFP-N1 eukaryotic vector using CloneExpressIIOne Step Cloning Kit (Vazyme, Nanjing, China). Similarly, the pEGFP-N1-EtSAG4-16-22 plasmid was constructed according to CloneExpress Multis One Step Cloning Kit (Vazyme, Nanjing, China). Amplified products were evaluated by electrophoresis with $1 \%$ agarose gels, observed by ethidium bromide staining, sequenced by Tianyi Huiyuan Biotechnology Co., Ltd (Wuhan, China) and 
demonstrated through blast analysis in NCBI (https://www. ncbi.nlm.nih.gov/).

\section{Expression and purification of rEtSAG16 and 22 protein}

pET-28a-EtSAG16 and pET-28a-EtSAG22 plasmids amplified in Transetta (DE3) (Quanshijin, Beijing, China) chemical competent cells. The expression of recombinant SAG proteins was induced by adding $1.0 \mathrm{mM}$ isopropyl $\beta$ D-thiogalactoside (IPTG, BS044B, Biosharp, Hefei, China) to DE3 cells at log-phase. The condition of gathering bacterial cells was $8000 \mathrm{rpm}$ for $10 \mathrm{~min}$. Then, sediment was suspended by adding buffer A (Tris-HCl 50 $\mathrm{mmol} / \mathrm{L}$, EDTA $0.5 \mathrm{mmol} / \mathrm{L}, \mathrm{NaCl} 50 \mathrm{mmol} / \mathrm{L}, 5 \%$ glycerol and DTT $0.5 \mathrm{mmol} / \mathrm{L}$ ), and fragmented by ultrasonic crusher. Oxidative $(50 \mathrm{mmol} / \mathrm{L})$ and reductive glutathione $(100 \mathrm{mmol} / \mathrm{L})$ was added into solutions obtained in previous steps to degenerate and renature rEtSAG16 and 22 proteins from the insoluble portion. Next, purification of rEtSAG16 and 22 proteins was performed using dialysis buffer (Tris- $\mathrm{HCl} 50 \mathrm{mmol} / \mathrm{L}$, ethylene diamine tetraacetic acid (EDTA) $0.5 \mathrm{mmol} / \mathrm{L}, \mathrm{NaCl} 50 \mathrm{mmol} / \mathrm{L}, 5 \%$ glycerol) and sucrose. Purity and concentration of obtained targeted proteins were analysed by $12 \%(\mathrm{w} / \mathrm{v})$ sodium dodecyl sulfate-polyacrylamide gel electrophoresis (SDS-PAGE) and BCA protein assay kit (P0012, Beyotime, Shanghai, China). Finally, rEtSAG16 and 22 proteins were preserved at $-80^{\circ} \mathrm{C}$ until use.
The preparation and verification of rEtSAG16 and 22 proteins

Twenty 14-day-old cobb broilers 500 were divided into two groups, averagely and fed referring to the method described previously. Chickens of experimental groups were challenged with E. tenella sporulated oocysts $\left(5.0 \times 10^{4}\right)$ via oral administration. Blood collected from the wing vein of chickens was centrifuged at $4500 \mathrm{rpm}$ for $3 \mathrm{~min}$ to obtain serum after 15 days post-challenge (Hoan et al. 2016). Serum was stored at $-20^{\circ} \mathrm{C}$ until use.

Western blot was used to demonstrate expressions of rEtSAG16 and 22 proteins according to the standard method with minor adjustments (Towbin et al. 1979). Firstly, separated SDS-PAGE was moved to polyvinylidene fluoride (PVDF) membranes (Merck, Millipore Ltd., Tullagreen, Carrigtwohill, Co. Cork, IRL) through a wet transfer method. Then, the PVDF membrane was blocked by $1 \%(\mathrm{w} / \mathrm{v})$ albumin of bovine serum with Tween 20 and Tris-buffered saline (TBST) at $4^{\circ} \mathrm{C}$ for $2 \mathrm{~h}$. Firstly, TBST was used to wash the PVDF membrane for three times. Secondly, the PVDF membrane was incubated with antiE. tenella polyclonal antibody serum (dilutions 1:300), uninfected serum (dilutions 1:300) and anti-His-tag monoclonal antibody (dilutions 1:2000) (Beyotime Co., LTD Shanghai, China) at $4{ }^{\circ} \mathrm{C}$ overnight, respectively. Thirdly, the washing process of the PVDF membrane was repeated for five times. Horseradish peroxidase (HRP)-conjugated goat anti-chicken immunoglobulin $\mathrm{G}$ (dilutions 1:2000) (Biosynthesis Co., LTD, Beijing, China) and goat anti-
Table 1 Primer sequences of PCR amplification

\begin{tabular}{ll}
\hline Primer & Sequences $\left(5^{\prime} \rightarrow 3^{\prime}\right)$ \\
\hline EtSAG4F* & CAACAAGCTGCTACTCC \\
EtSAG4R & AGGGCCCACTGGGGAAACTT \\
EtSAG16F & GGTGCAATCATCACTCG \\
EtSAG16R & TGAACCTGCCTGCCGCTGCA \\
pET28a-EtSAG16F & TGACTGGTGGACAGCAAATGGGTGCAATCATCACTCGCTC \\
pET28a-EtSAG16R & TTGTTAGCAGCCGGATCTCATCATGAACCTGCCTGCCG \\
& CTGCA \\
pEGFP-N1-EtSAG16F & CGGACTCAGATCTCGAGCTCATGGGTGCAATCATC ACTCG \\
EtSAG22F & ATGGTGGCGACCGGTGGATCTGAACCTGCCTGCC GCTGCA \\
EtSAG22R & GCGCTTTCCCTTCGTTC \\
pET28a-EtSAG22F & GCCTGCTTCCAATCCCCATG \\
pET28a-EtSAG22R & TGACTGGTGGACAGCAAATGGCGCTTTCCCTTCGTTC \\
pEGFP-N1-EtSAG22F & TTGTTAGCAGCCGGATCTCATCAGCCTGCTTCCAATCCCCATG \\
pEGFP-N1-EtSAG22R & CGGACTCAGATCTCGAGCTCATGGCGCTTTCCCTT CGTTC \\
pEGFP-N1-EtSAG4-16-22F & ATGGTGGCGACCGGTGGATCGCCTGCTTCCAATCC CCATG \\
pEGFP-N1-EtSAG4-16-22R & CGGACTCAGATCTCGAGCTCATGCAACAAGCTGC TACTCC \\
\hline
\end{tabular}

*Primers of EtSAG4 refer to the report of Zhao et al. (Zhao et al. 2020). ${ }^{\text {a }}$ Primers of truncated EtSAG16 and 22

${ }^{\mathrm{b}}$ Primers of prokaryotic expression. ${ }^{\mathrm{c}}$ Primers of eukaryotic expression 
mouse IgG (dilutions 1:2000) (Beyotime, Shanghai, China) were added to incubate with the PVDF membrane at $37^{\circ} \mathrm{C}$ for $2 \mathrm{~h}$. Finally, the secondary antibody was removed and washing progress was repeated. Antibody bounds on the PVDF membrane were tested utilising Electro-Chemi-Luminescence (ECL) kit (Juneng, Wuhan, China), according to manufacturer instructions.

\section{The construction of DNA vaccines pEGFP-N1-EtSAG16, pEGFP-N1-EtSAG22 and pEGFP-N1-EtSAG4-16-22}

Transfection of eukaryotic plasmid was performed based on methods mentioned by Liu et al. (Liu et al. 2013). One microgramme of DNA plasmid or $2 \mu$ lipofectamine 2000 (Thermo Fisher Scientific, Waltham, MA, USA) were diluted into $50 \mu \mathrm{l}$ serum-free and antibiotic-free medium (Thermo Fisher Scientific, Waltham, MA, USA) at room temperature for $5 \mathrm{~min}$, respectively. Then, $50 \mu \mathrm{l}$ diluted DNA and $50 \mu$ lipofectamine were mixed at room temperature for $20 \mathrm{~min}$. 293 T cells are a cell line originating from the human renal epithelial cell and saved in the parasitic laboratory of Huazhong Agricultural University. $10^{6} 293 \mathrm{~T}$ cells, $100 \mu \mathrm{l}$ mixture obtained from the previous step, and $500 \mu 11640$ medium were added into 35 -mm culture plates. The $293 \mathrm{~T}$ cells were cultured at $37^{\circ} \mathrm{C}$ with $5 \% \mathrm{CO}_{2}$ for $6 \mathrm{~h}$. Next, 1640 medium (Thermo Fisher Scientific, Waltham, MA, USA) containing $10 \%$ foetal bovine serum (Thermo Fisher Scientific, Waltham, MA, USA) was used to replace the original solution in culture pates. 293T cells were cultured under the same condition for $24 \mathrm{~h}$ and observed under a fluorescence microscope (Olympus Instruments, Tokyo, Japan).

\section{RT-PCR assay and western blot analysis of pEGFP-N1- EtSAG16, pEGFP-N1-EtSAG22 and pEGFP-N1-EtSAG4- 16-22 plasmids}

Total RNA was extracted from $293 \mathrm{~T}$ cells that had been transfected with pEGFP-N1-EtSAG16, pEGFP-N1EtSAG22 and pEGFP-N1-EtSAG4-16-22 plasmids by TRIzol reagent (Invitrogen, Carlsbad, CA, USA) according to the manufacturer instructions. Segments of EtSAG16, EtSAG22 and EtSAG4-16-22 were detected by the RTPCR method. Primers of RT-PCR are shown in Table 1. Amplified products were detected by electrophoresis with $1 \%$ agarose gel and visualised by ethidium bromide staining. Meanwhile, western blot was performed according to the procedure described previously. Briefly, proteins of 293T cells were extracted using cell lysis buffer (P0013, Beyotime, Shanghai, China), separated and purified by SDS-PAGE. Purified proteins were transferred to PVDF membranes. Mouse anti-green fluorescent protein tag (anti-GFP tag) monoclonal antibody (dilutions 1:2000) (Proteintech Group, Inc, Chicago, USA) was used as a primary antibody. HRP-conjugated goat anti-mouse IgG (dilutions 1:2000) (Beyotime Co., LTD Shanghai, China) was the secondary antibody. Finally, the antibody bound
Table 2 Grouping and immune procedure of animal experiments

\begin{tabular}{llll}
\hline Groups & Immunisation $^{\mathrm{a}}$ & Dose $(\mu \mathrm{g})$ & Challenge $^{\mathrm{b}}$ \\
\hline $\mathrm{G} 1$ & rEtSAG16 protein & 50 & E. tenella sporulated oocysts $\left(5.0 \times 10^{4}\right)$ \\
G2 & rEtSAG16 protein & 100 & E. tenella sporulated oocysts $\left(5.0 \times 10^{4}\right)$ \\
G3 & rEtSAG22 protein & 50 & E. tenella sporulated oocysts $\left(5.0 \times 10^{4}\right)$ \\
G4 & rEtSAG22 protein & 100 & E. tenella sporulated oocysts $\left(5.0 \times 10^{4}\right)$ \\
G5 & PBS & $/$ & $/$ \\
G6 & PBS & $/$ & E. tenella sporulated oocysts $\left(5.0 \times 10^{4}\right)$ \\
G7 & pEGFP-N1-EtSAG16 plasmid & 50 & E. tenella sporulated oocysts $\left(5.0 \times 10^{4}\right)$ \\
G8 & pEGFP-N1-EtSAG16 plasmid & 100 & E. tenella sporulated oocysts $\left(5.0 \times 10^{4}\right)$ \\
G9 & pEGFP-N1-EtSAG22 plasmid & 50 & E. tenella sporulated oocysts $\left(5.0 \times 10^{4}\right)$ \\
G10 & pEGFP-N1-EtSAG22 plasmid & 100 & E. tenella sporulated oocysts $\left(5.0 \times 10^{4}\right)$ \\
G11 & pEGFP-N1-EtSAG4-16-22 plasmid & 50 & E. tenella sporulated oocysts $\left(5.0 \times 10^{4}\right)$ \\
G12 & pEGFP-N1-EtSAG4-16-22 plasmid & 100 & E. tenella sporulated oocysts $\left(5.0 \times 10^{4}\right)$ \\
G13 & Empty pEGFP-N1 plasmid & 100 & E. tenella sporulated oocysts $\left(5.0 \times 10^{4}\right)$ \\
G14 & Endotoxin-free elution buffer & $/$ & $/$ \\
G15 & Endotoxin-free elution buffer & $/$ & E. tenella sporulated oocysts $\left(5.0 \times 10^{4}\right)$ \\
\hline
\end{tabular}

${ }^{\text {a }}$ Recombinant or DNA vaccine was inoculated at 14-day-old chicken in experiment groups firstly. Booster immunisations were done according to the same way at 7 dpi (21 days of age). ${ }^{\text {b }}$ Chicken of experiment groups were challenged with E. tenella sporulated oocysts $\left(5.0 \times 10^{4}\right)$ at 14 dpi (28 days of age) 

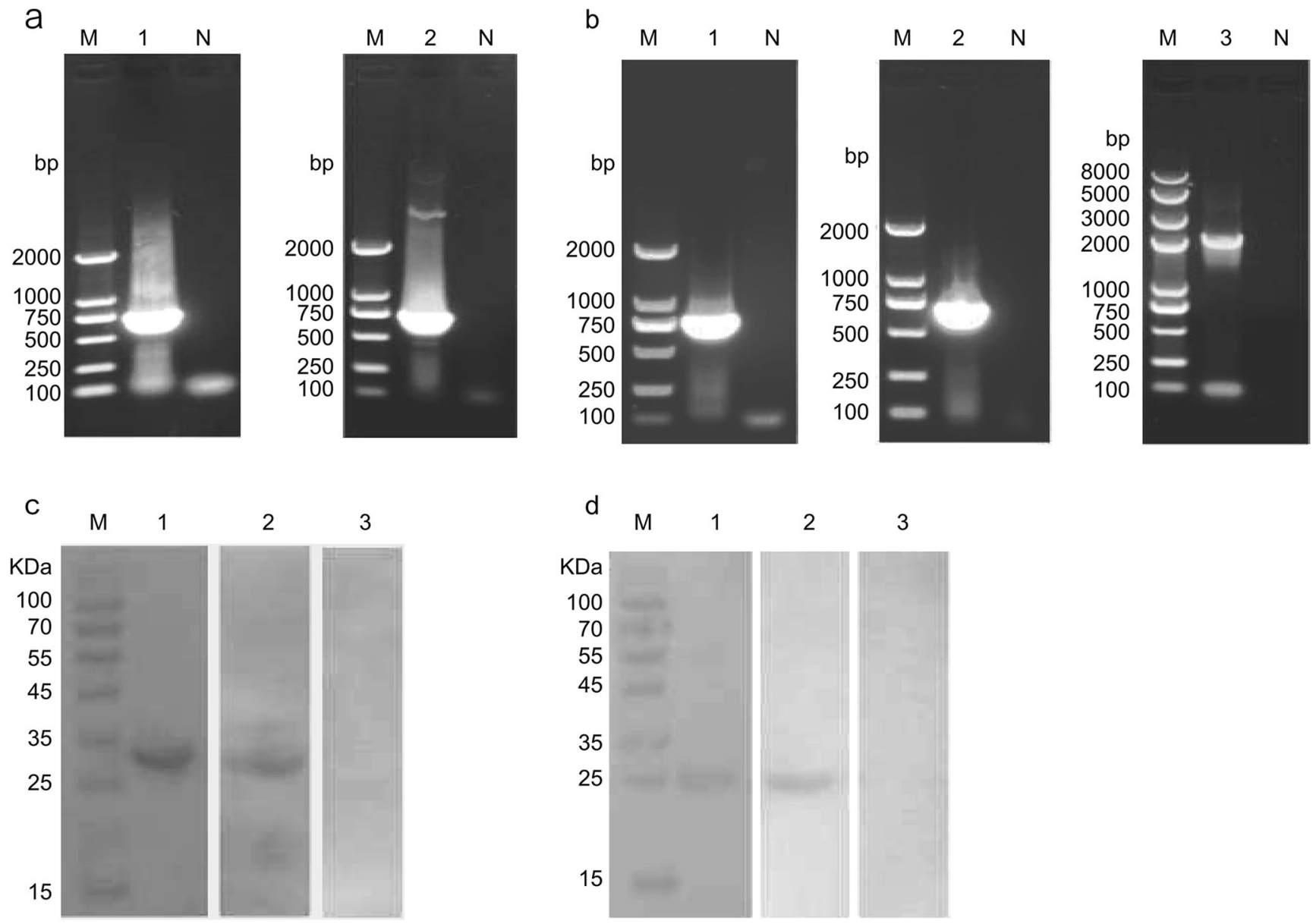

Fig. 1 a Agarose gel electrophoresis of EtSAG16 and 22 gene PCR products from pET-28a prokaryotic vector. Lane M: DNA marker; lane N: negative control; lane 1: EtSAG16 gene; lane 2: EtSAG22 gene. b Agarose gel electrophoresis of PCR product of EtSAG16, EtSAG22 and EtSAG4-16-22 genes from 293T cells. Lane M: DNA marker; lane N: negative control; lane 1: EtSAG16 gene; lane 2: EtSAG22 gene; lane 3:

EtSAG4-16-22 gene. c, d Western blot analysis of rEtSAG16 and 22 proteins. Lane M: protein marker; lane 1: protein probed by His tag as primary antibody; lane 2: protein probed by serum from chicken infected with $E$. tenella as primary antibody; lane 3: protein probed by serum of uninfected chicken as the primary antibody. c rEtSAG16 protein. d rEtSAG22 protein

on PVDF membranes was detected using the ECL kit (Juneng, Wuhan, China).

\section{Animal trail}

Grouping and immune procedure of animal experiments are shown in Table 2. Fourteen days of age cobb broilers 500 (numbers $=120$ ) were weighed and divided into 15 groups averagely (named as G1-G15). Chickens of G1-G4 groups were immunised with rEtSAG16 or 22 proteins $(50 \mu \mathrm{g}$ or $100 \mu \mathrm{g}$ ) by chest intramuscular injection. Chickens of G7G12 groups were vaccinated with pEGFP-N1-EtSAG16, pEGFP-N1-EtSAG22 and pEGFP-N1-EtSAG4-16-22 plasmid according to the same method. Moreover, G5, G6, G14 and G15 groups were used as uninfected or infected control groups. The G13 group received empty pEGFP-N1 plasmid as a plasmid control group. A booster immunisation was given at 7 days post-immunisation ( $7 \mathrm{dpi}$ ) for all immunised groups. All chickens except uninfected control groups (G5 and G14) were challenged with $E$. tenella sporulated oocysts $\left(5.0 \times 10^{4}\right)$ by oral administration on the 14th day post the primary vaccination (28 days of age). Meanwhile, all chickens were euthanised by injecting excess phenobarbital intravenously at 35 days of age.

\section{The detection of cytokine concentration and serum antibody}

Chicken blood was collected at 28 days of age and was centrifuged at $4500 \mathrm{rpm}$ for $3 \mathrm{~min}$ to obtain serum. The concentration of interferon- $\gamma$ (IFN- $\gamma$ ), interleukin-4 (IL-4), interleukin-10 (IL-10), interleukin-17 (IL-17) and total IgY antibody level in serum were detected through an indirect enzyme-linked immunosorbent assay (ELISA) utilising Chick Cytokine ELISA Quantitation Kits (catalogue numbers: CSB-E08550Ch, CSB-E06756Ch, CSB-E12835C, CSBE04607Ch and CSB-E11635Ch for IFN- $\gamma$, IL-4, IL-10, IL- 
a

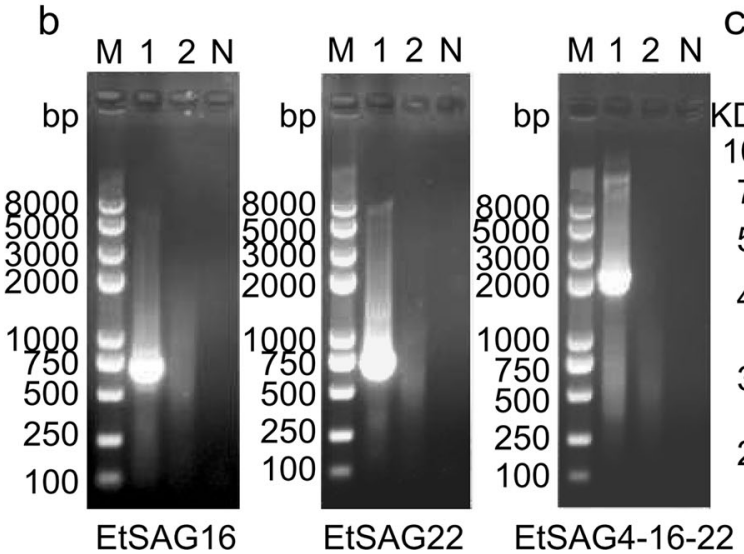

Fig. 2 a Fluorescence image under the microscope. (1) lipofectamine control; (2) empty pEGFP-N1 plasmid; (3) pEGFP-N1-EtSAG16; (4) pEGFP-N1-EtSAG22; (5) pEGFP-N1-EtSAG4-16-22. b RT-PCR assay of EtSAG16, EtSAG22 and EtSAG4-16-22 gene. Lane M: DNA marker; lane N: negative control; lane 1: target gene; lane 2: pEGFP-N1 plasmid.

17 and IgY respectively; CUSABIO, Wuhan, China), according to manufacturer instructions.

\section{Immunoprotective evaluation in vivo}

Immunoprotective of recombinant protein and DNA vaccine for chickens was evaluated through body weight gain, caecum lesion score, oocyst shedding and $\mathrm{ACI}$ value (Morehouse and Baron 1970). Body weight gain of chicken equals the final weight at 35 days of age subtracted by the initial weight at 1 day of age. Independent observers estimate caecum lesion scores according to the method described by Reid and Johnson (Johnson and Reid 1970). Oocysts per gramme (OPG) were counted from caecum content under a microscope according to McMaster counting technique (Long et al. 1976). ACI value as a comprehensive parameter can reflect the general body condition of chicken. ACI value is calculated through the formula: (relative rate of weight gain + survival rate) - (lesion value + oocyst value). Different ACI values show variation in anticoccidial levels: ACI $>180$ means adequate protection; $160<\mathrm{ACI}<179$ means moderate protection; $120<\mathrm{ACI}<159$ means limited protection; $\mathrm{ACI}<120$ means insufficient protection (Mcmanus et al. 1968). c Western blot analysis of EtSAG16, EtSAG22 and EtSAG4-16-22 gene expression in 293 T cells. Lane M: protein marker; lane 1: pEGFP-N1EtSAG4-16-22; lane 2: pEGFP-N1-16; lane 3: pEGFP-N1-EtSAG22; lane 4: pEGFP-N1; lane N: negative control

\section{Statistical analysis}

C-terminal hydrophobic GPI signal-anchor and N-terminal hydrophobic signal peptide of EtSAG16 and 22 were predicted using online software SignalIP (http://www.cbs.dtu.dk/ services/SignalP/) and big-PI predictor (http://mendel.imp. ac.at/gpi/gpi_server.html). Data were analysed by SPSS statistical software (SPSS for windows 25.0, SPSS Inc., Chicago, IL, USA) and Graphpad Prism 8.0 (software Inc., La Jolla, CA, USA). Differences among groups were tested with one-way ANOVA and Duncan multiple ranges $(p<0.05$ was considered significantly different).

\section{Results}

\section{Cloning and plasmid construction of EtSAG16, EtSAG22 and EtSAG4-16-22}

Truncated segments of EtSAG4, EtSAG16 and EtSAG22 were amplified from cDNA by PCR. Amplified bands showed in Fig. $1 \mathrm{a}$ and $\mathrm{b}$ demonstrate that EtSAG16 (693bp), EtSAG22 (663bp) and EtSAG4-16-22 (2004bp) had been 
Fig. 3 Serum cytokine concentration and IgY antibody level of rEtSAG16 and 22 proteins. Serum was collected at 14 dpi (28 days of age). G1: rEtSAG16 (50 $\mu \mathrm{g})$; G2: rEtSAG16 (100 $\mu \mathrm{g})$; G3: rEtSAG22 $(50 \mu \mathrm{g})$; G4: rEtSAG22 $(100 \mu \mathrm{g})$; G5: negative control group; G6: positive control group. a IFN- $\gamma$ concentration. b IgY concentration. $\mathbf{c}$ IL4 concentration. d IL-10 concentration. e IL-17 concentration. Bars represent mean $\pm \mathrm{SD}$ value $(N=8)$. Different alphabet responses significant difference among groups a

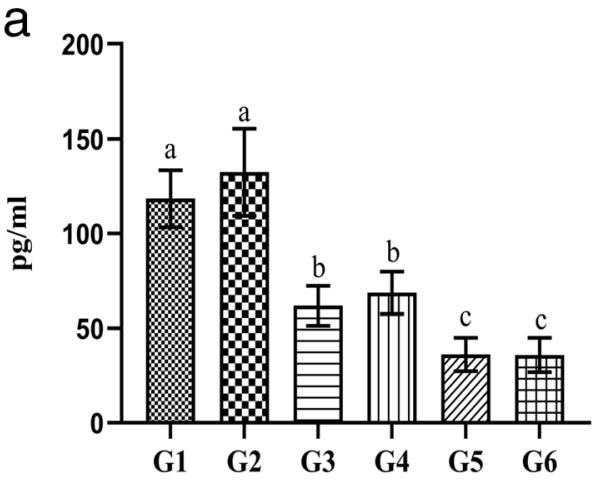

IFN- $\gamma$ concentration

C

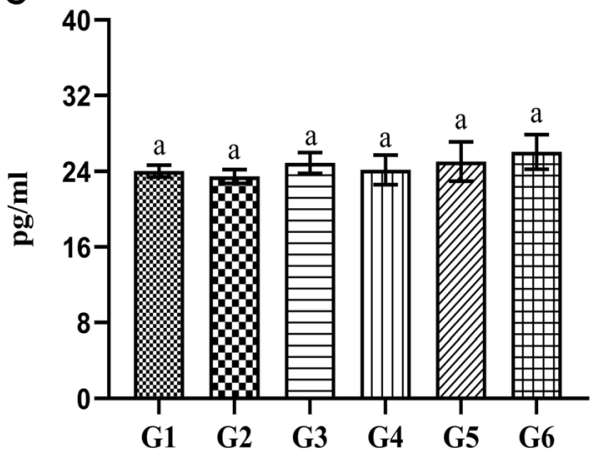

IL-4 concentration



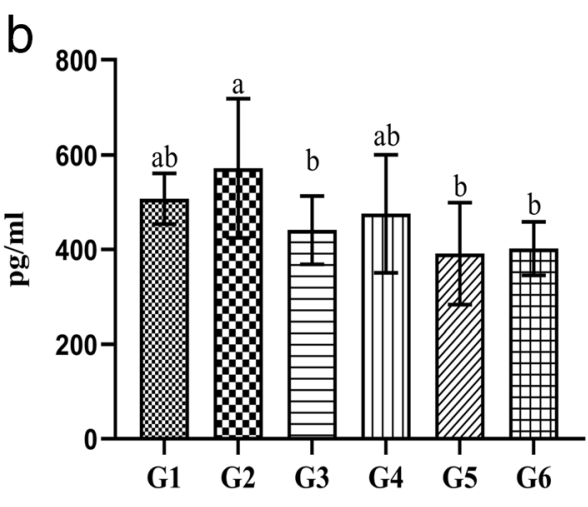

IgY concentration

d

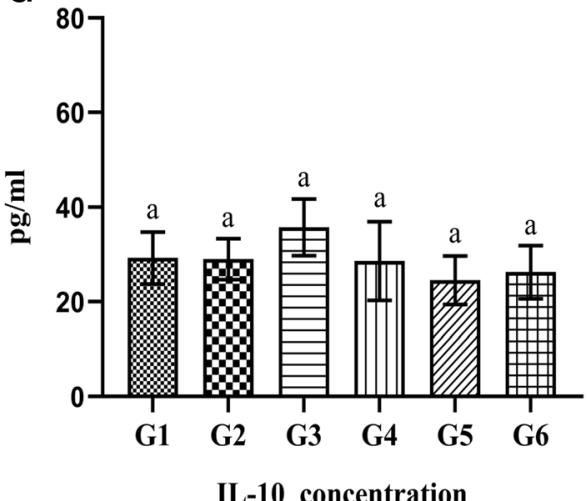

cloned into pET-28a prokaryotic and pEGFP-N1 eukaryotic vector successfully. EtSAG4, EtSAG16 and EtSAG22 gene sequences were identical to the Houghton strain of E. tenella (SAG4: AJ586535.1; SAG16: AJ586542.1; SAG22: AJ586551.1).

\section{Western blot analysis of rEtSAG16 and 22 protein}

Recombinant EtSAG16 and 22 proteins were detected by SDS-PAGE and purified by sucrose concentration and glutathione renaturation. Anti-E. tenella serum and anti-His-tag monoclonal antibody were used to demonstrate successful expressions of rEtSAG16 and 22 proteins by western blot experiment. Antibody bounds were accorded with the expected molecular mass of rEtSAG16 (27KDa) and 22 proteins $(25 \mathrm{KDa})$. As a contrast, there was no antibody bound in control groups (Fig. 1c, d)

\section{Eukaryotic expression of EtSAG16, EtSAG22 and EtSAG4-16-22 DNA plasmids}

The 293T cells transfected with pEGFP-N1-EtSAG16, pEGFP-N1-EtSAG22, pEGFP-N1-EtSAG4-16-22 or pEGFP-N1 plasmid successfully showed green fluorescence 
under the fluorescence microscope because of the existence of the GFP tag (Fig. 2a). Results of RT-PCR and western blot demonstrated successful expression of EtSAG16, EtSAG22 and EtSAG4-16-22 multiple genes in 293T cells (Fig. 2b, c). 293 T cells with empty pEGFP-N1 plasmid produced an antibody bound about $27 \mathrm{kDa}$ (GFP tag). Interestingly, there were two redundant bands in $293 \mathrm{~T}$ cells transfected with pEGFPN1-EtSAG16 plasmid, which might occur enzymolysis during the protein translation process. SAG4-16-22 recombinant protein containing SAG4 $(26 \mathrm{kDa})$, SAG16 $(27 \mathrm{kDa})$ and SAG22 (25 kDa) presented an antibody bound about $105 \mathrm{kDa}$ (containing $27 \mathrm{kDa}$ GFP tag), which was identical with the expected molecular mass.

\section{Immune responses induced by vaccines}

All chickens show no differences at the initial time of animal experiment in cytokine concentration and serum antibody level (data not shown). IgY antibody level and cytokine concentration of chickens (28 days of age) after secondary immunisation are shown in Figs. 3 and 4. IFN- $\gamma$ concentration of EtSAG16, EtSAG22 and EtSAG4-16-22 recombinant protein or DNA vaccine immune groups were higher than that of control groups $(p<0.05)$ (Figs. 3a and 4a). Besides, chicken vaccinated with $p E G F P-N 1-E t S A G 16, p E G F P-N 1-E t S A G 22$ or pEGFP-N1-EtSAG4-16-22 plasmid revealed significantly increased IgY antibody and IL17 expression compared to
Fig. 4 Serum cytokine concentration and IgY antibody level of pEGFP-N1-EtSAG16, pEGFP-N1-EtSAG22 and pEGFP-N1-EtSAG4-16-22 plasmids. Serum was collected at 14 dpi (28 days of age). G7: pEGFPN1-EtSAG16 $(50 \mu \mathrm{g})$; G8: pEGFP-N1-EtSAG16 (100 $\mu \mathrm{g})$; G9: pEGFP-N1-EtSAG22 (50 $\mu \mathrm{g})$; G10: pEGFP-N1-EtSAG22 $(100 \mu \mathrm{g})$; G11: pEGFP-N1EtSAG4-16-22 (50 $\mu \mathrm{g})$; G12: pEGFP-N1-EtSAG4-16-22 (100 $\mu \mathrm{g})$; G13: empty pEGFP-N1 control; G14: negative control group; G15: positive control group. a IFN- $\gamma$ concentration. b IgY concentration. c IL-4 concentration. d IL-10 concentration. e IL-17 concentration. Bars represent mean \pm sd value $(N=8)$. Different alphabet responses significant difference among groups

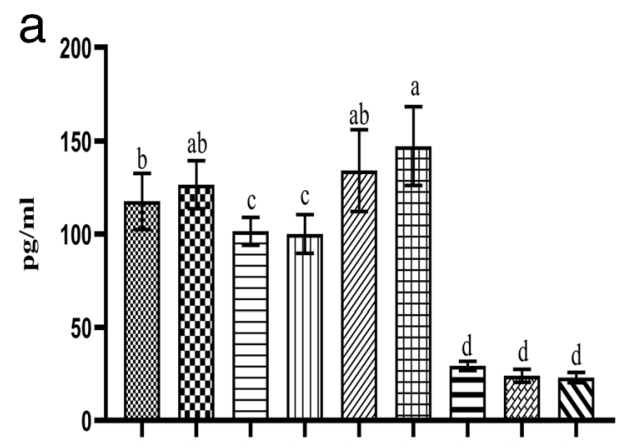

G7 G8 G9 G10 G11 G12 G13 G14 G15

IFN $-\gamma$ concentration
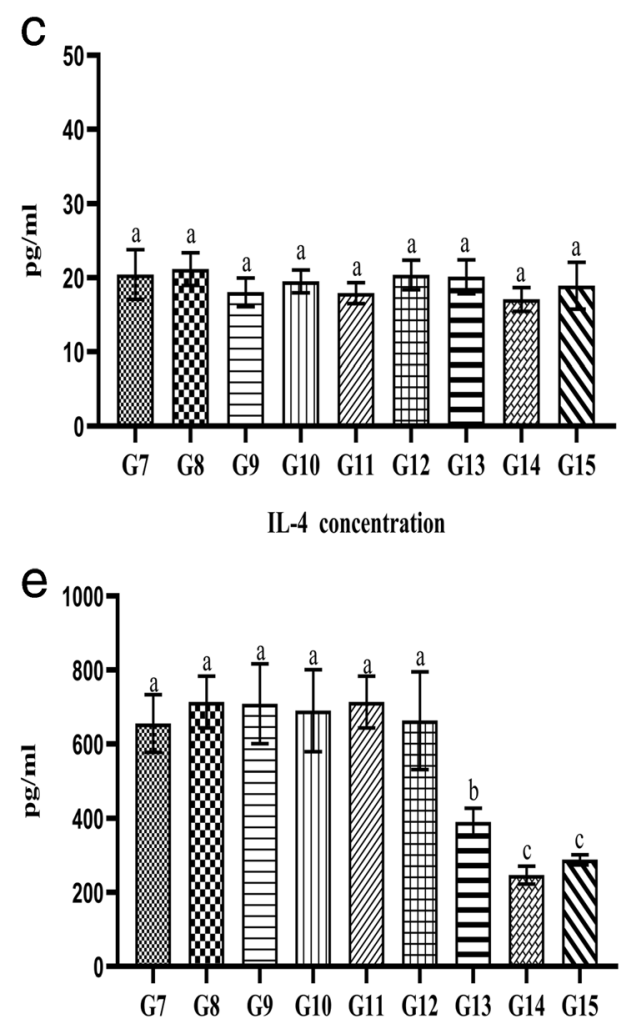

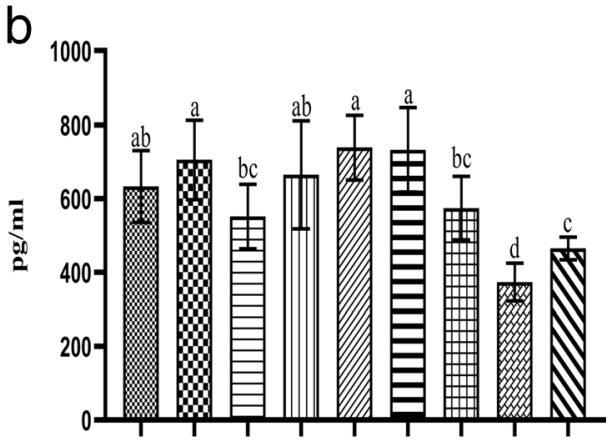

G7 G8 G9 G10 G11 G12 $\quad$ G13 $\quad$ G14 G15

IgY concentration

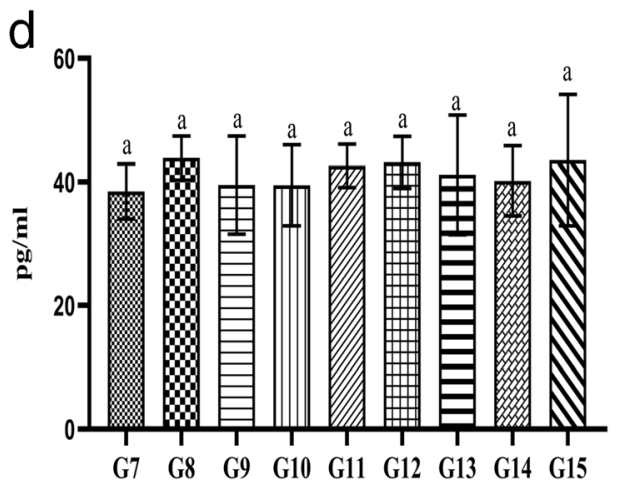

IL-10 concentration

IL-17 concentration 
control groups likewise $(p<0.05)$ (Fig. $4 \mathrm{~b}, \mathrm{e})$. However, there are no significant differences for IL-4 and IL-10 expression among all groups (Figs. 3c, d and 4c, d).

\section{Immunoprotective of EtSAG16, EtSAG22 and EtSAG4- $16-22$ in vivo}

All immunised groups show higher body weight gain, reduced oocyst output and lower caecum lesion score compared with infected control groups (Table 3). There were weak effects on improvement of immunoprotection when increasing immune dosage of vaccines. ACI value of the pEGFP-N1-EtSAG4-1622 plasmid $(50 \mu \mathrm{g})$ immune group was the highest in all experimental groups (173.11) providing moderated protection for chicken.

\section{Discussion}

Eimeria tenella, as a pathogenic responsible for chicken coccidiosis, is responsible for significant economic loss to the poultry industry (Shirley et al. 2005; Williams 1999). Novel genetic engineering approaches have been used to generate subunit protein and DNA-based vaccines to replace chemical drugs and traditional live coccidium vaccines. pcDNA3-SO7 constructed by cloning the $\mathrm{SO} 7$ gene of $E$. tenella was the first DNA vaccine against $E$. tenella infection (Kopko and Martin 2000). Polyhistidine-tagged fusion proteins of $E$. tenella coded by EtMIC1 and EtMIC2 gene can induce IgG antibody response, reduce oocyst shedding and increase weight gain
(Sathish et al. 2012). Multivalent epitope DNA vaccines (pVAX1-NA4-1-TA4-1-LDH-2-EMCDPK-1) protect chickens against multiple pathogens, including E. tenella, E. necatrix, E. maxima and E. acervuline (Song et al. 2015b).

Surface antigens (SAGs) function as adhesion and invasion during parasite infection (Lekutis et al. 2001). However, there are few studies regarding EtSAG genes of E. tenella. Therefore, in the present study, SAG16 and SAG22 of E. tenella were selected as target genes to evaluate their immunoprotective effect in chicken. Besides, a panel of multiple genes (EtSAG4-16-22), comprising EtSAG4, EtSAG16 and EtSAG22, was used to explore the synergistic protective effect of EtSAG genes. Western blot and RT-PCR assays demonstrated successful expression of recombinant proteins and DNA vaccines based on EtSAG16, EtSAG22 and EtSAG4-16-22. Meanwhile, the western blot results also indicated that rEtSAG16 and rEtSAG22 proteins could be identified by anti-E. tenella polyclonal antibody. It was consistent with the results of recombinant surface antigen 5401 of E. tenella (Song et al. 2015a).

Cell-mediated and humoral immunity play essential roles in defending against E. tenella infection (Cacho et al. 2016; Dalloul and Lillehoj 2006). CD4+ T cells, IL-12 and IFN- $\gamma$ cytokines are considered primary effectors to inhibit apicomplexan (Brake 2002). IFN- $\gamma$ is secreted from innate lymphoid and natural killer cells and helps the host eliminate intracellular pathogens during cellular immune response (Dalton et al. 1993; Hunter et al. 1995). IL-4 has been implicated in extracellular parasite infection or allergens (Vivier et al. 2018). IL-17 secreted by Th17 cells contributes to

Table 3 Protective efficacy of rEtSAG16, 22 protein and pEGFP-N1-EtSAG16, pEGFP-N1-EtSAG22 and pEGFP-N1-EtSAG4-16-22 DNA plasmids

\begin{tabular}{|c|c|c|c|c|c|}
\hline Groups & Average body weight gains (g) & Relative body weight gain (\%) & Oocyst shedding $\left(10^{5}\right)$ & Mean lesion scores & Anticoccidial index \\
\hline Negative (G5) & $202.63 \pm 43.60^{\mathrm{a}}$ & 100.00 & $0.00^{\mathrm{d}}$ & $0 \pm 0^{\mathrm{d}}$ & 200.00 \\
\hline Positive (G6) & $96.38 \pm 33.29^{d}$ & 47.56 & $1.47 \pm 0.02^{\mathrm{a}}$ & $3.55 \pm 0.25^{\mathrm{a}}$ & 72.06 \\
\hline G1 & $180.38 \pm 18.50^{\mathrm{b}}$ & 89.02 & $0.79 \pm 0.02^{\mathrm{c}}$ & $1.75 \pm 0.38^{\mathrm{c}}$ & 157.52 \\
\hline $\mathrm{G} 2$ & $180.50 \pm 62.74^{\mathrm{b}}$ & 89.08 & $0.72 \pm 0.028^{\mathrm{c}}$ & $1.43 \pm 0.22^{\mathrm{c}}$ & 166.78 \\
\hline G3 & $191.50 \pm 55.16^{\mathrm{a}}$ & 94.51 & $1.16 \pm 0.057^{\mathrm{b}}$ & $2.40 \pm 0.30^{\mathrm{b}}$ & 145.51 \\
\hline G4 & $177.75 \pm 42.87^{\mathrm{c}}$ & 87.72 & $0.79 \pm 0.290^{\mathrm{c}}$ & $2.22 \pm 0.42^{\mathrm{b}}$ & 152.52 \\
\hline Negative (G14) & $132.50 \pm 23.18^{\mathrm{b}}$ & 100.00 & $0.00^{\mathrm{f}}$ & $0 \pm 0^{\mathrm{g}}$ & 200.00 \\
\hline Positive (G15) & $71.00 \pm 48.35^{\mathrm{g}}$ & 53.58 & $1.79 \pm 0.035^{\mathrm{a}}$ & $3.47 \pm 0.19^{\mathrm{a}}$ & 78.88 \\
\hline G7 & $121.50 \pm 29.82^{\mathrm{d}}$ & 91.70 & $0.78 \pm 0.042^{\mathrm{d}}$ & $2.08 \pm 0.18^{\mathrm{b}}$ & 153.90 \\
\hline G8 & $141.25 \pm 28.31^{\mathrm{a}}$ & 106.60 & $0.89 \pm 0.064^{\mathrm{c}}$ & $2.27 \pm 0.31^{\mathrm{b}}$ & 164.90 \\
\hline G9 & $134.00 \pm 21.97^{\mathrm{b}}$ & 101.13 & $0.75 \pm 0.078^{\mathrm{d}}$ & $1.73 \pm 0.15^{\mathrm{c}}$ & 167.83 \\
\hline G10 & $117.50 \pm 18.63^{\mathrm{e}}$ & 88.68 & $0.49 \pm 0.099^{\mathrm{e}}$ & $1.04 \pm 0.12^{\mathrm{e}}$ & 168.28 \\
\hline G11 & $132.38 \pm 33.96^{\mathrm{b}}$ & 99.91 & $0.73 \pm 0.247^{\mathrm{d}}$ & $1.58 \pm 0.18^{\mathrm{d}}$ & 173.11 \\
\hline G12 & $127.88 \pm 24.09^{\mathrm{c}}$ & 96.51 & $0.46 \pm 0.071^{\mathrm{e}}$ & $1.76 \pm 0.33^{\mathrm{c}}$ & 168.91 \\
\hline G13 & $106.25 \pm 28.90^{f}$ & 80.19 & $1.65 \pm 0.050^{\mathrm{b}}$ & $3.55 \pm 0.14^{\mathrm{a}}$ & 109.79 \\
\hline
\end{tabular}

Different letters indicated that mean is significantly different among groups for the same tandem parameters $(p<0.05$, mean $\pm \mathrm{sd}$, sd: standard deviation). G5 and G6 groups are control groups for rEtSAG16 and 22 protein. G14 and G15 groups are control groups for pEGFP-N1-EtSAG16, pEGFP-N1EtSAG22 and pEGFP-N1-EtSAG4-16-22 DNA plasmids 
eliminating pathogens responsible for varied infectious diseases (Korn et al. 2009). We measured IgY level and cytokine concentration using ELISA to analyse humoral and cellmediated immune responses in chickens. Our results showed that chickens administered with DNA vaccines showed significantly high IFN- $\gamma$ and IL-17 levels than that of infected control groups, which indicated production of cell-mediated immunity $(p<0.05)$. In our study, rEtSAG16 induced a higher IFN- $\gamma$ expression than rEtSAG22 $(p<0.05)$, thereby revealing that it might be more effective in inhibiting $E$. tenella. The level of IgY was significantly increased in groups challenged with DNA vaccine rather than the groups challenged with recombinant protein. Therefore, we infer that humoral immunity induced by rEtSAG16 and 22 proteins is weak. IgY antibody is predominant immunoglobulin in chicken serum and possesses equivalent function as IgG antibody of mammals (Warr et al. 1995). Chickens fed with IgY antibodies from hyperimmune sources are protected against $E$. tenella and E. maxima infections (Lee et al. 2009). Therefore, a high IgY antibody level induced by EtSAG16, EtSAG22 and EtSAG4-16-22 DNA vaccines might help chickens against E. tenella infection. We did not observe any differences in concentrations of IL-4 and IL-10 in all tested groups. Besides, cytokine concentrations and IgY antibody level of the pEGFP-N1-EtSAG4-16-22 plasmid immunised group were almost the same as that of the pEGFP-N1-EtSAG16 immunised group, indicating that the synergy of EtSAG4, 16 and 22 genes were weak and ineffective.

In our study, all chickens survived from infection experiments. Both recombinant protein and DNA vaccine based on EtSAG16, EtSAG22 and EtSAG4-16-22 show higher weight gain, reduced oocyst output and declined caecum lesion scores compared with infected control groups. Notably, body weight gains of chickens challenged with pEGFP-N1EtSAG16 $(100 \mu \mathrm{g})$ and pEGFP-N1-EtSAG22 $(50 \mu \mathrm{g})$ were higher than that of uninfected control groups, thus demonstrating that EtSAG16 and 22 DNA vaccines could counteract effects of $E$. tenella on chicken weight. Further, there was a weak positive correlation between immunoprotective effect and immunising dose for recombinant protein and DNA vaccine based on EtSAG16, EtSAG22 and EtSAG4-16-22. The pVAX1-m1-m2-s1-s2 plasmids (cocktail DNA vaccine) containing four fragments of $E$. tenella sporozoite antigen $\mathrm{SO} 7$ and merozoite antigen MZ5-7 showed a high ACI value (189.92) against E. tenella infection and provided better protection compared with the plasmid coding a single segment (Song et al. 2015c). However, although the highest ACI value (173.11) was observed in the pEGFP-N1-EtSAG4-16-22 plasmid $(50 \mu \mathrm{g})$ group, it provided just moderate protection to chickens in this study. Moreover, there was no significant improvement in the immunoprotective effect of cocktail DNA vaccine $p E G F P-N 1-E t S A G 4-16-22$. It might be attributed to differences in target genes. Finally, the immunoprotective effect and immunogenicity of EtSAG16 were superior to EtSAG22 whether recombinant protein or DNA vaccine.

Recombinant protein and DNA vaccine designed based on E. tenella SAG16, SAG22 and SAG4-16-22 genes can provide moderated protection to chicken against $E$. tenella infection and motivate cell-mediated and humoral immunity in chickens. In conclusion, our research provided potential therapeutic modalities for controlling coccidiosis.

Author contribution Conceptualisation, formal analysis, funding acquisition, methodology and project administration, RF; investigation, PZ, $\mathrm{CW}, \mathrm{YX}, \mathrm{YH}$ and $\mathrm{LZ}$; supervision, JD, CZ, YZ and JZ; writing the original draft, PZ. All authors have read and consented to publish the manuscript.

Funding Thanks for the funding support provided by the national key research and development program "Research on detection and control technology of key pathogens in livestock and poultry" (subject no. 2016YFD0501303).

\section{Declarations}

All animal experiments conformed to relevant provisions of the ethical committee of Huazhong Agricultural University, referring to stipulations of the care and use of laboratory animals in China.

Conflict of interest The authors declare no competing interests.

\section{References}

Ajioka JW et al (1998) Gene discovery by EST sequencing in Toxoplasma gondii reveals sequences restricted to the Apicomplexa. Genome Res 8:18-28

Blake DP, Tomley FM (2014) Securing poultry production from the everpresent Eimeria challenge. Trends Parasitol 30:12-19

Brake DA (2002) Vaccinology for control of apicomplexan parasites: a simplified language of immune programming and its use in vaccine design. Int J Parasitol 32:509-515

Bülow R, Boothroyd JC (1991) Protection of mice from fatal Toxoplasma gondii infection by immunisation with p30 antigen in liposomes. $\mathrm{J}$ Immunol 147:3496-3500

Cacho ED, Gallego M, Lillehoj HS, Quilez J, Lillehoj EP, SánchezAcedo C (2016) Induction of protective immunity against experimental Eimeria tenella infection using serum exosomes. Vet Parasitol 224:1-6

Chapman HD, Jeffers TK (2014) Vaccination of chickens against coccidiosis ameliorates drug resistance in commercial poultry production. Int J Parasitol Drugs Drug Resist 4:214-217

Dalloul RA, Lillehoj HS (2006) Poultry coccidiosis: recent advancements in control measures and vaccine development. Expert Rev Vaccines 5:143-163

Dalton DK, Pitts-Meek S, Keshav S, Figari IS, Bradley A, Stewart TA (1993) Multiple defects of immune cell function in mice with disrupted interferon-gamma genes. Science 259:1739-1742

Hoan TD, Zhang Z, Huang J, Yan R, Song X, Xu L, Li X (2016) Identification and immunogenicity of microneme protein 2 (EbMIC2) of Eimeria brunetti. Exp Parasitol 162:7-17

Hunter C, Chizzonite R, Remington J (1995) IL-1 beta is required for IL12 to induce production of IFN-gamma by NK cells. A role for IL-1 
beta in the $\mathrm{T}$ cell-independent mechanism of resistance against intracellular pathogens. J Immunol 155:4347-4354

Ivory C, Chadee K (2004) DNA vaccines: designing strategies against parasitic infections. Genet Vaccines Ther 2:17

Jahn D et al (2009) Model structure of the immunodominant surface antigen of Eimeria tenella identified as a target for sporozoiteneutralising monoclonal antibody. Parasitol Res 105:655-668

Johnson J, Reid WM (1970) Anticoccidial drugs: lesion scoring techniques in battery and floor-pen experiments with chickens. Exp Parasitol 28:30-36

Kopko SH, Martin DS (2000) Responses of chickens to a recombinant refractile body antigen of Eimeria tenella administered using various immunising strategies. Poult Sci 79:336-342

Korn T, Bettelli E, Oukka M, Kuchroo VK (2009) IL-17 and Th17 cells. Annu Rev Immunol 27:485-517

Lai L et al (2011) The role of sialyl glycan recognition in host tissue tropism of the avian parasite Eimeria tenella. PLoS Pathog 7: e1002296

Lee SH, Lillehoj HS, Park DW, Jang SI, Lillehoj EP (2009) Protective effect of hyperimmune egg yolk IgY antibodies against Eimeria tenella and Eimeria maxima infections. Vet Parasitol 163:123-126

Lekutis C, Ferguson DJP, Grigg ME, Camps M, Boothroyd JC (2001) Surface antigens of Toxoplasma gondii: variations on a theme. Int J Parasitol 31:1285-1292

Lesa C et al (2014) A review of coccidiostats and the analysis of their residues in meat and other food. Meat Sci 97:358-374

Lillehoj HS, Ding X, Dalloul RA, Sato T, Yasuda A, Lillehoj EP (2005) Embryo vaccination against Eimeria tenella and E. acervulina infections using recombinant proteins and cytokine adjuvants. $\mathrm{J}$ Parasitol 91:666-673

Liu Y, Li J, Zhang X (2013) Protective immunity induced by a DNA vaccine encoding Eimeria tenella rhomboid against homologous challenge. Parasitol Res 112:251-257

Long PL, Millard BJ, Joyner LP, Norton CC (1976) A guide to laboratory techniques used in the study and diagnosis of avian coccidia. Folia Vet Lat 6:201-217

Mcmanus EC, Campbell WC, Cuckler AC (1968) Development of resistance to quinoline coccidiostats under field and laboratory conditions. J Parasitol 54:1190-1193

Morehouse NF, Baron RR (1970) Coccidiosis: evaluation of coccidiostats by mortality, weight gains, and fecal scores. Exp Parasitol 28:25-29

Ramly NZ, Rouzheinikov SN, Sedelnikova SE, Baker PJ, Chow YP, Wan KL, Nathan S, Rice DW (2013) Crystallisation and preliminary crystallographic analysis of a surface antigen glycoprotein, SAG19, from Eimeria tenella. Acta Crystallogr 69:1380-1383

Reid AJ, Blake DP, Ansari HR, Billington K, Browne HP, Bryant J, Dunn M, Hung SS, Kawahara F, Miranda-Saavedra D, Malas TB, Mourier T, Naghra H, Nair M, Otto TD, Rawlings ND, Rivailler P, Sanchez-Flores A, Sanders M, Subramaniam C, Tay YL, Woo Y, Wu X, Barrell B, Dear PH, Doerig C, Gruber A, Ivens AC, Parkinson J, Rajandream MA, Shirley MW, Wan KL, Berriman M, Tomley FM, Pain A (2014) Genomic analysis of the causative agents of coccidiosis in domestic chickens. Genome Res 24:16761685

Sathish K et al (2012) Plant expressed coccidial antigens as potential vaccine candidates in protecting chicken against Coccidiosis. Vaccine 30:4460-4464
Shirley MW (2010) Development of a live attenuated vaccine against coccidiosis of poultry. Parasite Immunol 11:117-124

Shirley MW, Smith AL, Tomley FM (2005) The biology of avian Eimeria with an emphasis on their control by vaccination. Adv Parasitol 60:285

Smith RR, Ruff MD (1975) A rapid technique for the cleaning and concentration of Eimeria oocysts. Poult Sci 54:2081-2086

Song X, Huang X, Yan R, Xu L, Li X (2015a) Efficacy of chimeric DNA vaccines encoding Eimeria tenella 5401 and chicken IFN- $\gamma$ or IL-2 against coccidiosis in chickens. In: The 13th academic seminar of veterinary parasitology branch of Chinese animal husbandry and veterinary association.

Song X, Ren Z, Yan R, Xu L, Li X (2015b) Induction of protective immunity against Eimeria tenella, Eimeria necatrix, Eimeria maxima and Eimeria acervulina infections using multivalent epitope DNA vaccines. Vaccine 33:2764-2770. https://doi.org/10. 1016/j.vaccine.2015.04.052

Song X, Xu L, Yan R, Huang X, Li X (2015c) Construction of Eimeria tenella multi-epitope DNA vaccines and their protective efficacies against experimental infection. In: The 13th academic seminar of veterinary parasitology branch of Chinese animal husbandry and veterinary association.

Tabarés E, Ferguson D, Clark J, Soon P-E, Wan K-L, Tomley F (2004) Eimeria tenella sporozoites and merozoites differentially express glycosylphosphatidylinositol-anchored variant surface proteins. Mol Biochem Parasitol 135:123-132

Tian L et al (2017) Protective efficacy of coccidial common antigen glyceraldehyde 3-phosphate dehydrogenase (GAPDH) against challenge with three Eimeria species. Front Microbiology 8:1245

Towbin H, Staehelin T, Gordon J (1979) Electrophoretic transfer of proteins from polyacrylamide gels to nitrocellulose sheets: procedure and some applications. Proc Natl Acad Sci U S A 102:459-471

Vivier E, Artis D, Colonna M, Diefenbach A, di Santo JP, Eberl G, Koyasu S, Locksley RM, McKenzie ANJ, Mebius RE, Powrie F, Spits H (2018) Innate lymphoid cells: 10 years on. Cell 174:1054 1066

Warr GW, Magor KE, Higgins DA (1995) IgY: clues to the origins of modern antibodies. Immunol Today 16:392-398

Williams RB (1998) Epidemiological aspects of the use of live anticoccidial vaccines for chickens. Int J Parasitol 28:1089-1098

Williams RB (1999) A compartmentalised model for the estimation of the cost of coccidiosis to the world's chicken production industry. Int J Parasitol 29:1209-1229

Williams RB (2002) Anticoccidial vaccines for broiler chickens: pathways to success. Avian Pathol 31:317-353

Zhang ZC, Huang JW, Li MH, Sui YX, Wang S, Liu LR, Xu LX, Yan RF, Song XK, Li XR (2014) Identification and molecular characterization of microneme 5 of Eimeria acervulina. PLoS One 9:e115411

Zhao P, Li Y, Zhou Y, Zhao J, Fang R (2020) In vivo immunoprotective comparison between recombinant protein and DNA vaccine of Eimeria tenella surface antigen 4. Vet Parasitol 278:109032. https://doi.org/10.1016/j.vetpar.2020.109032

Publisher's note Springer Nature remains neutral with regard to jurisdictional claims in published maps and institutional affiliations. 